\title{
As peles da fotografia: fenômeno, memória/arquivo, desejo
}

\section{ETIENNE SAMAIN}

\section{Resumo}

O ensaio se propõe refletir sobre algumas dimensões profundas que fazem da fotografia um evento e uma revelação mas também um lugar de memórias, um arquivo vivo do tempo. Trataremos, deste modo, de interrogar as imagens e de lhes perguntar (enquanto arqueólogo e visionário que somos) o que significa pensar com elas a história humana e imaginar com elas nosso próprio futuro.

Palavras-chave:

Tempos da imagem, memória e arquivo, Antropologia e arte, Georges Didi-Huberman 


\title{
The skins of the picture: phenomenon, memory/archive, desire
}

\author{
ETIENNE SAMAIN
}
Abstract
The essay proposes to reflect on some deeper dimensions that make photography an event and a revelation but also a place of memories, a life time connected to other file.

Keywords: and file, Anthropology and art, Georges Didi-Huberman 


\section{1."Cascas" ou como levantar e abrir um questionamento}

Junho de 2011. Um domingo de manhã cedo, na Polônia. Um pequeno livro Écorces: 70 páginas, 19 imagens fotográficas, 19 curtos capítulos. Um mês para terminar o 'relato-photo' de uma deambulação à Auschwitz- Birkenau. Um título vegetal: Cascas. Seu autor, Georges Didi-Huberman (2011b), filósofo e historiador da arte, visita pela primeira vez o campo de exterminação onde seus avôs morreram. O livro inicia-se:

Pousei três pedacinhos de casca [de bétula] sobre uma folha de papel. Olhei. Olhei pensando que olhar me ajudaria talvez a ler algo que nunca tinha sido escrito. Olhei os três pequenos fragmentos como se fossem as três letras de uma escrita - anterior a todo alfabeto. Ou talvez, como o começo de uma carta a ser escrita; mas para quem? [...] . São três fragmentos arrancados de uma árvore há algumas semanas, na Polônia. Três fragmentos de tempo. Meu próprio tempo em seus pedaços; um pedaço de memória, essa coisa não escrita que procuro ler; um pedaço do presente, aí sob os meus olhos, sobre a branca página; um pedaço de desejo, a carta para escrever, mas para quem? (grifos meus).

Descobrir o tempo da imagem, o tempo na imagem. Falar do tempo plural presente na imagem, em todas as imagens quando, fortes e firmes, nos colocam em relação com elas, quando, humanas, nos convocam a olhar nossa história e nosso destino como sendo este tempo heterogêneo composto de passado, de presente e de futuro. Quando, recusando-se de 
nos dizer de antemão o que elas pensam e pensarão conosco, se oferecem e se oferecerão, no nosso presente, ao mesmo tempo, como revelações, como memórias e como desejos. Eis o que será o argumento central deste ensaio.

O que foram as imagens na minha vida e por que precisei de tanto tempo para depositar nelas minha confiança? Recordo-me, no entanto, de algumas imagens "sagradas" da minha infância. Entre elas, essa imagem, musical e quase uterina, das ondas (ora potentes, ora repousadas) quando o mar avançava, quando se retirava. A imagem, também, de um pequeno carro vermelho com pedais que tinha visto, no final da segunda guerra mundial, dirigido por um menino da minha idade. Um carro com que sonhei mas, sobretudo, com o qual fiz viagens extraordinárias na "campagne", nas "montanhas", nos "subterrâneos" do pequeno quintal da família, um dos territórios da minha infância.

Meu relativo interesse para com as imagens permanece, deste modo, paradoxal. Ao mesmo tempo vivia delas e, ao mesmo tempo, não me preocupava muito com elas.

Procuro possíveis razões. É, talvez, por eu ter nascido na escrita, no meio dos livros e das bibliotecas, numa cultura (a pós-segunda guerra mundial) predominantemente marcada pela escrita. Não descarto, porém, o fato de que, no período de minha alfabetização, não tenha sido dada suficiente relevância ao mundo das imagens. Na balança do conhecimento, elas não tinham um verdadeiro peso. Não eram consistentes. As letras, as palavras, as frases, elas sim. Sabiam se organizar, obedeciam a regras, a ordens, a gramáticas. Eram disciplinadas, sérias e confiáveis, por serem domáveis.

As imagens, iguais a borboletas, voavam, passavam. Chegavam e, logo, iam embora. De um lado, um movimento das pálpebras e dos cílios, uma piscadela; de outro, um bater de asas, apenas. Efêmeras, fugazes, sempre de passagem, as imagens, tanto quanto as borboletas, não mudarão tão cedo. Permanecerão inquietantes, intrigantes e insistentes.

Devo procurar outras razões por ter acordado tão lentamente para o mundo plural das imagens. Precisava descobrir que Aristóteles não é Platão, que a poesia é uma escrita nômade. Precisava mergulhar nos mitos de sociedades indígenas ágrafas para me dar conta que essas produções sofisticadas de 
um pensamento selvagem (e, no entanto, "científico") eram ninhos de imagens, verdadeiros roteiros fílmicos, jóias da observação e da imaginação.

Ia aprender, mais tarde, com Anne-Marie Christin (1995 e 2011) que a escrita é, de nascimento, uma dupla imagem. Que, longe de serem a mera transposição e codificação da fala, as figuras e os signos que a constituem não podiam emergir e tomar corpo senão a partir de um suporte, de um fundo, de uma tela branca, a qual era uma outra imagem.

Precisava, sobretudo, deste contexto histórico que presenciamos nesses últimos trinta anos: a chamada "civilização das imagens”, isto é, essa chuva de imagens que, ao mesmo tempo, nos provoca, nos ensina, nos inunda e nos satura. Imagens que chegam a nos fazer descobrir, é verdade, cantinhos de nossa aldeia planetária até que envesguemos. Imagens que, por outros motivos e segredos (de estado) nos mentem ou nos foram, de antemão, confiscadas. Imagens que nos iludem, nos fazem perder a visão e, mais gravemente, a consciência, isto é, o discernimento e a responsabilidade face à nossa própria história. Temos, assim, que redescobrir não apenas as funcionalidades heurísticas diversas das imagens, mas seus profundos e necessários valores de uso. Imperativos esses, que são tanto as condições, como as exigências de nosso futuro, nesta virada cognitiva e comunicacional da qual participamos.

Sempre gostei da máquina que fotografa, desse pequeno olho de ciclope, único e redondo, que nos ensina a ver quando perdemos de vista o bom uso de nossos dois olhos. Magnífica máquina que nos permite questionar, pensar, sonhar com o real.

A fotografia, todavia, permaneceu, desde minha adolescência, somente um hobby. Não a questionava diretamente. Interessei-me por ela em 1984 quando, com outros colegas, foi implantado, na Unicamp, o Programa de Pós-Graduação em Multimeios. Foi então que me debrucei sobre as imagens, sobre a imagem fotográfica em especial.

Levantei, de início, a questão de sua singularidade. Era óbvio que um desenho, uma fotografia, o fotograma de um filme, uma imagem videográfica, uma imagem numérica pertenciam ao mundo das imagens. Restava entender, todavia, que, se cada uma dessas "máquinas de imagens” era solidária e complementar das demais, cada uma, também, opera- 
va com originalidade e com potencialidades distintas. Este questionamento conduzia a um outro: a natureza, a essência da fotografia. Bastará lembrar aqui o que André Bazin intuía desde 1945, quando declarava que aquilo que, na sua essência, caracterizava a imagem fotográfica deveria ser procurado "não no resultado, mas na gênese [...] na moldagem, na inscrição da marca do objeto pela intermediação da luz" (XAVIER, 1983, p.124). Isso dito, foi necessário esperar a década de $8 \mathrm{o}-\mathrm{e}$ a melhor exploração que se tinha feito pouco antes, na França, da obra complexa de Charles Sanders Peirce (1839-1914) - para ver publicados, quase que sucessivamente, três importantes trabalhos sobre a fotografia: a Filosofia da Fotografia (1983) de Henri Vanlier; O Ato fotográfico (1983) de Philippe Dubois e A Imagem Precária. Do dispositivo fotográfico (1987) de Jean-Marie Schaeffer. Essas questões relativas à ontologia da imagem fotográfica me interessaram durante vários anos. Penso, hoje, após amplo debate relativo a essas obras, que convém perscrutar a fotografia (e toda imagem) sob outros ângulos.

Há mais de trinta anos, Roland Barthes publicava seu último livro, A Câmara clara. Nota sobre a fotografia. O livro me tinha irritado logo após sua publicação (1980). Era por demais intimista. Rejeitei-o durante mais de dez anos por causa de sua subjetividade, sem ter-me dado conta de que os livros que agente abandona são muitas vezes livros que nos inquietam, nos perseguem e devem nos purificar. Isso se verificou.

Numa semana de 1995, sem saber até hoje a verdadeira razão, reli várias vezes, sucessivamente, esta obra de 48 pequenos capítulos de um discurso amoroso. Pouco depois escrevi (1998, p.115-128) um longo artigo que era uma espécie de dívida, uma demanda de redenção, mas, sobretudo, uma homenagem a Barthes. De fato, com a Câmara clara, passava-se de uma ontologia da imagem (fotográfica) a uma fenomenologia da imagem.

Nesses dias, mais uma vez, reabri essa obra lendária. Logo, noto o que Barthes escrevia: "Nessa procura sobre a Fotografia, a fenomenologia emprestava-me, então, um pouco de seu projeto e um pouco de sua linguagem. Mas era uma fenomenologia vaga, desenvolta, cínica mesmo, de tal forma aceitava ela deformar ou esquivar seus princípios segundo o arbítrio de minha análise" (1984, p.37-38). 
Este afeto ia se tornar, sabemos, o "Punctum", que Barthes instalava ao lado do "Studium" (a imagem enquanto "campo de estudo") da fotografia.. Acrescentava: «Como Spectator, eu só me interessava pela Fotografia como 'sentimento'; eu queria aprofundá-la, não como uma questão (um tema), mas como uma ferida: vejo, sinto, portanto, noto, olho e penso" (p. 39).

Georges Didi-Huberman em Cascas (ao qual aludi no começo deste ensaio) e em sua obra gigantesca e inconfundível (que, com urgência, temos que descobrir) nos propulsiona, nas pistas abertas por Barthes, em direção a novos horizontes: ousar, agora, olhar para a imagem - apesar de tudo - como sendo, ao mesmo tempo, paixões e questões. Fazer delas os "olhos da historia" (DIDI-HUBERMAN, 2009b; 2010; 2011a), isto é, tanto suas montagens, como suas desmontagens e necessárias remontagens. Com poucas palavras: tomar, com elas, "posição".

\section{As imagens são "fenômenos"}

As imagens pertencem à ordem das coisas vivas, ao mesmo título que os problemas de beleza, os caranguejos do mar, as orquídeas e os seres humanos. Explico-me. Se admitirmos que a imagem (toda imagem) é um fenômeno, isto é, "algo que vem à luz [phanein]", "algo que advém", um "acontecimento" (um "advento" como melhor se dizia, outrora), entender-se-ia que ela é, ainda, uma "epifania", uma "aparição" [epiphanein], uma "revelação", no sentido até fotográfico do termo.

A imagem é um fenômeno na medida em que torna sensível todo um processo que combina aportes dos mais variados. Tomemos como exemplo a imagem fotográfica. A que processo combinatório ela deve sua existência? Para se moldar, precisou de um suporte: uma máquina captadora de luz, jogos de lentes, diafragma e obturador, uma placa sensível. Para se construir, precisou de uma pessoa, do seu talento, de sua maneira de observar, de pensar e de expressar o que viu, de enquadrar, de retocar, de manipular. Para emergir, ela precisou da existência do tempo, do espaço, da luz e da sombra, das cores, das linhas, dos volumes, das formas, do ambiente... Em poucas palavras, a fotografia precisou da longa história de uma "aventura" icônica. Para viver enquanto imagem, foi necessária a existência de espectador(es), isto é, de seres vivos, "aptos a saberem olhar uma imagem [...], capazes de discernir 'lá onde ela arde"” (DIDI-HUBERMAN, 2006a, p. 33). 
Se admitirmos, deste modo, que toda imagem pertence à grande família dos fenômenos, não poderemos mais equiparar uma imagem a uma bola de sinuca ou a um prego que a tábua engole quando, nela, o martelo bate. Sem chegar a ser um sujeito, a imagem é muito mais que um objeto: ela é o lugar de um processo vivo, ela participa de um sistema de pensamento. A imagem é pensante.

Creio, assim, não fabular ao emprestar de Gregory Bateson reflexões que poderiam servir à emergência de uma nova epistemologia da imagem, quando ele escreve que "as idéias que se encontram nos fenômenos - não somente as idéias que estão na minha cabeça, mas as idéias que se entrecruzam nos fenômenos organizados - se apresentam em forma de camadas" (2000, p. 318). Acrescentaria: a imagem participa, a sua maneira, do mistério, da complexidade e da profundidade que habitam as bonecas russas, as belas matrioshkas que contêm e escondem outras bonecas - da ordem de sete ou mais - cada uma menor, todas participando de um tempo anacrônico, quase mítico. $\mathrm{O}$ importante é o fato de que essas bonecas se encaixam num movimento materno e matricial expandido no tempo. O tempo da imagem nunca será o tempo da história.

A imagem, assim entendida, é longe de ser uma abstração. Ela é a eclosão de significações, num fluxo, amplo e contínuo, de pensamentos que sabe carregar. É por essa razão que a imagem pode-se tornar um clarão numa noite profunda, a aparição de uma espécie fantasmal esquecida, que, de repente, se desvela por um curto instante, se revela, nos lembra de outros tempos e de outras memórias.

O tempo das imagens é um pouco como o tempo dos rios e das nuvens. Ele rola, corre, murmura, quando não se cala. $\mathrm{O}$ que faríamos sem as imagens?

\section{As imagens são memórias}

O que as imagens nos mostram nunca será um pensamento único e definitivo. Eis que o cérebro - como assinala justamente Gilles Deleuze (2003, p.264) - é a “tela da imagem”. É com este cérebro - suas lembranças, suas memórias e esquecimentos nele contidos - que toda imagem se choca, arrebentando uma espiral de novas e outras operações sensoriais, cognitivas e afetivas.

Para falar do "trabalho da memória", tal como o entendo, proponho compará-lo ao "trabalho do mar", isto é, a esse incessante movimento das ondas, a esse ritmo relojoeiro de seus fluxos e refluxos. 
Uma metáfora que poderia servir a expressar o que é uma imagem quando é criadora: uma varredura de tempos anacrônicos dos quais não conhecemos nem as origens, nem as andanças, nem os destinos. Além da questão do "movimento", a analogia com o "trabalho do mar" poderia se estender em outras direções: os "mistérios do mar", os "segredos do mar", os "silêncios do mar", esse guardião de destroços, de náufragos e de tesouros, de histórias e de outras memórias.

A imagem, em especial a imagem fixa, é complexa. Para se dar conta disso, basta prolongar o tempo de um olhar posto sobre ela, sobre sua face visível para, logo, descobrir que a imagem nos leva em direção a outras profundidades, outras estratificações, ao encontro de outras imagens. É necessário, pois, abrir a imagem, desdobrar a imagem, "inquietar-se diante de cada imagem" (DIDI-HUBERMAN, 2006b). Furar e romper a superfície.

Pois, é verdade, não olhamos da mesma maneira uma fotografia ou as imagens que um filme desenrola. Nossas posturas são fenomenologicamente diversas.Ver um filme não é olhar para uma fotografia. São atos de observação, posições do olhar, distintas. "Assiste-se" a um filme, "mergulha-se" numa fotografia. De um lado, um olhar horizontal, do outro, um olhar vertical, abissal. Enquanto as imagens projetadas levam o espectador num fluxo temporal contínuo, que procura seguir e entender, as fotografias, por sua vez, o fixam num congelamento do tempo do mundo e o convidam a entrar na espessura de uma memória. Diante da tela, somos viajantes e navegadores; diante da fotografia, tornamo-nos analistas e arqueólogos.

Mas há de se ir mais adiante. É necessário interrogar nossa maneira de olhar, questionar nossos próprios atos de olhar, nossos próprios olhos.

Em Écorces, Georges Didi-Huberman perambula dentro de Auschwitz-Birkenau, entre bétulas, fileiras de arames farpados que "aprisionam a vida como a vista". Ele cava, escava seus próprios olhos. Como gotas de água que filtram e infiltram-se no solo, ele penetra, então, "nessa vegetação na qual dorme uma imensa desolação humana [...], toda a louca lógica de uma organização da humanidade entendida como matéria, como resíduo a ser transformado". Afunda, finalmente, "nessas tranquilas superfícies pantanosas, [onde] repousam as cinzas de inúmeros assassinados" (p. 34-35). Acrescentará: "É necessário saber olhar como olha um arqueólogo. E é através de tal olhar 
- tal interrogação - sobre o que vemos que as coisas começam a olhar para nós de dentro de seus espaços enterrados e de seus tempos desaparecidos" (p.61). Lembrará Walter Benjamim: "a arqueologia não é apenas uma técnica para explorar o passado. É também e, sobretudo, uma anamnese para entender o presente [...], um bom relatório arqueológico não deve apenas indicar as camadas das quais provêm as descobertas e, sim, e, sobretudo, aquelas que, antes, foi preciso atravessar" (p.69).

As fotografias são tecidos, malhas de silêncios e de ruídos. Precisam de nós para que sejam desdobrados seus segredos. As fotografias são memórias, histórias escritas nelas, sobre elas, de dentro delas, com elas. É por essa razão, ainda, que as fotografias se acumulam como tesouros, dentro de pastas, de caixinhas, de armários, que elas se escondem dentro de uma carteira. Elas são nossos pequenos refúgios, os envelopes que guardam nossos segredos. As pequenas peles, as películas, de nossa existência. As fotografias são confidências, memórias, arquivos.

\section{A memória dos arquivos}

Ao reler, pela terceira vez, Écorces, dei-me o tempo de uma pausa. E de outro questionamento. O que, para mim, evocaria e representaria a palavra "arquivo"? Rapidamente me chegou a imagem (clássica) de um espaço de cor azul marinho (escuro), frio, abandonado, poeirento, com cheiro de mofo. Com poucas palavras, um lugar mortífero.

Logo depois (estava no meu escritório), me surpreendi ao descobrir que o meu lugar de trabalho era realmente um grande arquivo, desta vez um emaranhado de coisas preciosas, ainda vivas e das mais diversas (pastas, relatórios, cadernos, diários de campo, fotografias, correspondências guardadas, estantes de livros que até o diabo conseguiu ordenar minimamente e, ainda, pequenos objetos de que nunca se fala: um gancho de telefone, um teclado, um violão desafinado, uma mesa de trabalho, um chapéu de palha e um lenço de pescoço pendurados numa parede clara). Muitas coisas, entre desastres e constelações.

$\mathrm{O}$ arquivo, penso, é uma memória em latência, uma memória que cochila, que, encoberta, poderá ser, amanhã, descoberta, re-aberta. Uma memória, aliás, que nos habita a tal ponto, que se diz de uma pessoa assassinada que ele era um "arquivo vivo". Um arquivo é, na verdade, um pouco como um dicionário, essa coleção de unidades vivas de uma língua, enclausuradas no papel e, no entanto, sempre em movimento, como um balde de minhocas... 
Os arquivos do tempo (refiro-me concretamente, desta vez, às 19 fotografias recentes do que foi o campo de extermínio de Auschwitz-Birkenau, realizadas por Georges Didi-Huberman) são memórias de memórias. Memórias que, de novo, trabalham, que reacendem velhas lembranças e outras imagens e, com elas, sobretudo, interrogam nosso tempo presente. Essas fotografias, essas imagens não são mais simples objetos, nem meras lembranças. São questões e questionamentos postos ante o nosso dia-a-dia planetário. Elas são uma espécie de clarão na noite, um grito, um apelo, ao mesmo tempo recordação e convocação para aqueles que somos e para outros que nunca chegaremos a conhecer. Memórias que não morrem, que viajam, inquietas.

Ao lado da palavra "arquivo" deveriam, desta maneira, figurar duas outras palavras, duas profissões que, também, formaram-se em torno da raiz grega arkhé (começo). São elas: "arqueólogo" e "arquiteto". O arquivo não pertence somente ao passado, não é fadado a permanecer num mero plano de desconstrução e de exumação. Sempre, confessará o seu desejo de um futuro, isto é, um projeto de construção, de reconstrução possível, um recomeço. Os arquivos são, de certo modo, as articulações, as conjugações (passado simples, passado composto, presente, futuro, condicional, imperativo, particípio) e as declinações de nossas aventuras humanas,

Eles não são apenas lugares de lembranças redescobertas que precisariam de reanimações. Devem ser encarados como sendo inquietações e questões para pensar, interrogar, levantar nosso presente, o que melhor diz Jacques Derrida:

A questão do arquivo não é [...] uma questão do passado [...] É uma questão de futuro, a questão do futuro mesmo, a questão de uma resposta, de uma promessa e de uma responsabilidade para amanhã. $\mathrm{O}$ arquivo, se quisermos saber o que isto queria dizer, isso somente será de nosso conhecimento no tempo que há de vir (1995, p 60).

As memórias de arquivos são sempre questões postas diante de nossa história, interrogações que olham para nós.

\section{As imagens são desejos}

O que poderia desejar uma imagem, uma fotografia se é verdade que ela é um fenômeno que faz parte de todo de um sistema, de um circuito de pensamento? 
Ela quer ser criadora. Eis o que, sempre, deveria lhe ser próprio. Ela não gosta da banalização, desses dilúvios de imagens que conhecemos, excessos que nos cegam; ela não suporta as censuras e os amordaçamentos, privações que nos paralisam, nos silenciam e tornam-nos mudos. Deseja, desta forma, "tornar sensíveis, visíveis, relações de tempo que não se deixam ver no objeto representado e que não se deixam reduzir ao presente" (DELEUZE, 2003, p.330).

Ela pede que agente se "inquiete" diante dela, que, com ela, se saiba fazer a "experiência" do que significa uma imagem, "por exemplo a imagem de um soldado alemão que mata à queima-roupa uma mãe que segura sua criança nos braços [...], uma imagem que abre dentro de mim um mistério novo, uma inquietação maior, que, primeiro, é a inquietude do contato entre esta imagem e o real, do contato entre imagem e corpo, imagem e história, imagem e política..." (DIDI-HUBERMAN, 2006b). Ela demanda, desta sorte, que se olhe para ela "enquanto ela é um operador temporal de sobrevivências, portadora então de uma potência política que diz respeito ao nosso passado como à nossa 'atualidade integral', quer dizer, ao nosso futuro" (Didi-Huberman, 2009, p. 102).

Ela deseja ser contemplada, lá onde se origina, lá até onde chegará a desembocar, como procuram o arqueólogo e o visionário. Para tanto, ela deve ser desdobrada, aberta, revelada no seu intimo, na sua profundidade, lá onde ela "arde" [e /ou queima]: "saber olhar uma imagem significaria, de certa maneira, tornar-se capaz de discernir lá onde ela arde, lá onde sua eventual beleza reserva um espaço de um 'signo secreto', de uma crise não apaziguada, de um sintoma. Lá onde a cinza não esfriou" (DIDI-HUBERMAN, 2006a, p.33).

A imagem não é um objeto, não é uma coisa, Ela é um ato posto diante de nós, oferecido aos nossos destinos.

Ao fechar o pequeno livro Écorçes, Didi-Huberman deixa essa confidência (p.70): "A imagem, se fizermos a experiência de pensá-la como uma casca, é, ao mesmo tempo, um manto - um adorno, um véu - e uma pele, isto é, uma superfície de aparição dotada de vida, reagindo à dor e prometida à morte". Falava de Auschwitz- Birkenau, de um campo de exterminação.

Urge saber que as imagens são nossos olhos passados, presentes e futuros, olhos da história, roupas, nudezas e paredes da história. Roupagens e montagens de tempos heterogêneos. De vivências presentes, de sobrevivências, de ressurgências, de tantas outras memórias (individuais e coletivas). Pensar deste 
modo as imagens como lugares de questionamentos, lugares dentro dos quais, escrevemos, também, nossa história.

Campinas, Março de 2012

\section{Referências}

BATESON, Gregory. "The Cybernetics of 'Self': A Theory of Alcoholism", in Steps to an Ecology of Mind. Chicago, The University of Chicago Press, 2000 [primeira publicação em 1972], pp. 309-37.

BARTHES, Roland. La chambre Claire. Note sur la photographie. Paris: Cahiers du Cinéma-Gallimard-Seuil, 1980. Versão portuguesa: A câmara clara. Nota sobre a fotografia. Rio de Janeiro:Editora Nova Fronteira, $2^{\mathrm{a}}$ ed., 1984.

CHRISTIN, Anne-Marie. L'image écrite ou la déraison graphique. Paris: Flammarion (Idées et Recherches), 1995. Não existe ainda uma versão portuguesa L'invention de la figure. Paris:Flammarion, 2011.

DELEUZE, Gilles. Deux Régimes de Fous. Textes et Entretiens: 1975-1995 (Edição preparada por David Lapoujade), Paris: Les Èditions de Minuit, 2003.

DERRIDA, Jacques. Mal d'Archive: une impression freudienne. Paris:Éditions Galilée, 1995..

DIDI-HUBERMAN, Georges. "L'image brûle", in Penser par les images. Autour des travaux de Georges Didi-Huberman (org. Laurent Zimmemann). Nantes, Éditions Cécile Defaut, 2006a, pp. 11-51.

." s'inquiéter devant chaque image » (entrevista com Georges Didi-Huberman realizada por Mathieu Potte-Bonneville e Pierre Zaoui), in Vacarme, ํㅜ궁, outono de 2006b. http://www.vacarme.org/article121o.html . "Imaginer, Disloquer, Reconstruire », in Cannibalismes Disciplinaires. Quand l'histoire de l'Art et l'Anthropologie se rencontrent (orgs. Thierry Dufrêne e Anne-Christine Taylor). Paris, Musée du Quai Branly e INHA, 2010, pp. 189-195. . Survivance des lucioles. Paris: Les Éditions de Minuit, 2009a. Edição portuguesa: Sobrevivência dos vaga-lumes. Belo Horizonte: Editora UFMG, 2011.

.Quand les images prennent position. L'oeil de l'histoire, I. Paris: Les Éditions de Minuit, 20ogb.

.Remontages du temps subi. L'oeil de l'histoire, II. Paris: Les Éditions de Minuit, 2010. 
. Atlas ou le gai savoir inquiet. L'oeil de l'histoire, III.

Paris: Les Éditions de Minuit, 2011a.

.Écorces. Paris: Les Éditions de Minuit, 2011b.

DUBOIS, Philippe. L'Acte Photographique. Bruxelas: NathanLabor, 1983. Versão portuguesa. O Ato Fotográfico e outros ensaios. Campinas: Papirus Editora, $4^{\underline{a}}$ ed., 2000.

SAMAIN, Etienne. "Um retorno à Câmara Clara: Roland Barthes e a antropologia visual", in O Fotográfico (org. Etienne Samain). São Paulo: Editora Hucitec, 1998 e Editora SENAC, $2^{\mathrm{a}}$ ed., 2005.

SCHAEFFER, Jean-Marie. L'image précaire. Du dispositif photographique. Paris; Éditions du Seuil, 1987. Versão portuguesa. A imagem precária. Sobre o dispositivo fotográfco. Campinas: Papirus Editora, 1996.

VANLIER, Henri. Philosophie de la Photographie. Paris: Les Cahiers du Cinéma, 1983.

XAVIER, Ismail (org.). A Experiência do Cinema. Antologia. Rio de Janeiro: Ed.Graal-Embrafilme), 1983

Recebido em: 15/03/12

Aceito: 27/11/12

\section{ETIENNE SAMAIN}

samain@unicamp.br

Nasceu e se formou em Teologia na Bélgica. No Brasil desde 1973, tornou-se antropólogo e fotógrafo, convivendo com as comunidades Kamayurá (Alto Xingu, MT) e Urubu-Kaapor (Maranhão). Interessouse de modo amplo pelas imagens, daquelas presentes nas narrativas míticas às que são produzidas pelas novas tecnologias. Enquanto se esforçava para fazer da Antropologia uma ciência não só de palavras, acabou por aproximá-la da comunicação e da arte. É professor titular do Instituto de Artes da Unicamp, atuando no programa de Pós-Graduação em Multimeios, onde tem orientado pesquisas de mestrado e doutorado com forte presença experimental das imagens. Entre outros trabalhos, publicou o livro Moroneta-Kamayurá (1991) e organizou a coletânea $O$ fotográfico (2005). Com o suporte de bolsa produtividade do $\mathrm{CNPq}$, suas pesquisas recentes partem da obra de Gregory Bateson e de Aby Warburg para pensar a comunicação humana sob a perspectiva da Antropologia e da Epistemologia. Em 2012, organizou a coletânea Como pensam as imagens (Editora da Unicamp). 